This is a postprint version of the following published document:

N. Encinas, M. Pantoja, J. Abenojar, M.A. Martínez. Control of wettability of polymers by surface roughness modification. Journal of Adhesion Science and Technology, vol. 24, issue 11-12, 2010, pp. 1869-1883.

DOI: $10.1163 / 016942410 \times 511042$

(C) Koninklijke Brill NV, Leiden, 2010 


\title{
Control of Wettability of Polymers by Surface Roughness Modification
}

\author{
N. Encinas *, M. Pantoja, J. Abenojar and M. A. Martínez \\ Department of Science and Engineering of Materials and Chemical Engineering, IAAB Materials \\ Performance Research Group, Universidad Carlos III de Madrid, Av. Universidad 30, \\ 28911 Leganés, Spain
}

\begin{abstract}
Most polymeric materials, particularly polyolefins and their derivatives, present a low surface energy which is the cause of their poor wettability and limits processes such as adhesive bonding, painting, or metalizing. Many methods have been developed and used to modify polymer surfaces for improved wething, including mechanical treatments, wet-chemical treatments with strong acids or bases, and exposure to flames or corona discharge.

In this paper the improvement of wetting properties of several polymeric materials widely used in the automotive industry, such as high density polyethylene (HDPE), low density polyethylene (LDPE), polypropylene (PP) and silicone, is studied by means of surface mechanical abrasion using sandpapers of different grain sizes $(1000,180$ and 80$)$. Measurements of the surface roughness are performed using a Hommel Tester T8000 device equipped with a diamond stylus, which provides data on the aritlmetic average roughness $R_{\mathrm{a}}$ parameter and Abbott-Firestone curve. Variations in the polymers surface energy (SE) are estimated through contact angle measurements using five test liquids of different polarities. Both components of the SE, dispersion $\left(\sigma^{\mathrm{D}}\right)$ and polar $\left(\sigma^{\mathrm{P}}\right)$, as well as total $\left(\sigma^{\mathrm{T}}\right)$ at different conditions of treatment are analyzed using the Owens-Wendt-Rabel-Kaelble (OWRK) method. Morphological changes induced in the surface are analyzed by Scanning Electron Microscopy (SEM). Additionally, measurements of the static friction coefficient $\left(\mu_{s}\right)$ are carried out by the standard method ASTM D 1894-08. A slight enhancement in surface wettability is found with the mechanical abrasion pre-treatment from the SE increase. Finally, a higher value of $\mu_{\mathrm{s}}$ is achieved for the abraded specimens as the normal force acting onto the system is increased.
\end{abstract}

Keywords

Polymer surface abrasion, roughness, contact angle, wettability, surface energy

\section{Introduction}

Polymers are nowadays extensively used in many fields due to the wide range of properties and applicability they provide [1-4], which makes them adequate to be used, for example, in the automotive sector, in parts like bumpers (polypropy-

\footnotetext{
${ }^{*}$ To whom correspondence should be addressed. Tel.: +34-91-624-88-63; Fax: +34-91-624-94-40; e-mail: nencinas@ing.uc3m.es
} 
lene, polyurethane), seats (polyurethane foam), ceilings (fibr reinforced plastics), acoustic and vibration sealing (silicone, rubber), windows (polycarbonate), etc. [4]. The design and processing of plastic materials involves the use of additives which may produce differences in properties such as conductivity or roughness [5]. Polymeric surfaces, in general, present nonpolar characteristics, which imply low aff nity for a wide range of compounds such as adhesives [6], especially those of water-based and polar nature. Because of nonpolar characteristics, polymers, in general, possess low surface energy values [7-9]. The measurement of a liquid contact angle onto a solid surface is the most commonly used method to calculate the surface energy of the solid material [10], and it is based on the theory of contact angles of pure liquids on a solid developed by Young (equation (1)) [11]:

$$
\sigma_{\mathrm{s}}=\sigma_{\mathrm{sl}}+\sigma_{\mathrm{l}} \cdot \cos \theta \text {, }
$$

where $\sigma_{1}$ is the experimentally determined liquid surface tension, $\sigma_{\mathrm{s}}$ represent the solid surface energy (SE), $\gamma_{\mathrm{sl}}$ define the solid/liquid interfacial energy and $\theta$ is the liquid contact angle on the solid surface. Among all the different thermodynamic approaches for the calculation of $\sigma_{\mathrm{s}}$ (Zisman [12], Wu and Nancolla [13], Fowkes [14], harmonic mean equation [15], acid-base [16], etc.), here we have used the Owens-Wendt-Rabel-Kaelble (OWRK) $[17,18]$ approach. This method considers the total SE $\left(\sigma^{\mathrm{T}}\right)$ of a solid surface as a sum of all interactions at the solid/liquid interface, divided into two contributions, dispersion $\left(\sigma^{\mathrm{D}}\right)$, due to London interactions, and polar $\left(\sigma^{\mathrm{P}}\right)$. This mathematical model enables to obtain each component of the SE by means of a linear fittin of equation (2). In this expression, $\theta$ represents the test liquid contact angle, $\sigma_{1}$ and $\sigma_{\mathrm{s}}$ are the liquid surface tension and the solid SE, respectively, and the superscripts $\mathrm{D}$ and $\mathrm{P}$ refer to the dispersion and polar components of the SE:

$$
\frac{(1+\cos \theta) \sigma_{1}}{\sqrt{\sigma_{1}^{\mathrm{D}}}}=\sqrt{\sigma_{\mathrm{s}}^{\mathrm{P}}} \cdot \sqrt{\frac{\sigma_{1}^{\mathrm{P}}}{\sigma_{1}^{\mathrm{D}}}}+\sqrt{\sigma_{\mathrm{s}}^{\mathrm{D}}} .
$$

The condition for a liquid to spread on a solid surface (wetting condition) is $\sigma_{\mathrm{s}} \geqslant \sigma_{1}$. Thereby, the increase in SE of polymeric materials enhances paint or coating adhesion, as well as the durability of the adhesive joint, because it allows wetting of the entire area of the polymer and creates stronger molecular interactions. Because of this, it is necessary to pretreat polymer surfaces prior to subsequent adhesion processes. The main objectives of a surface treatment are to develop strength and durability in bonding by removing low cohesion layers on the adherend surface, achieve reproducible results and ensure adhesion. The choice of the surface treatment should consider several factors, including the size and geometry of surface, the necessary and available instrumentation, stability of material to be treated, and the possibility of surface migration. These processes include mechanical or chemical methods or exposure to $f$ ames and corona discharge [19-24].

The $f$ nal $f$ nish and texture of the surface determines the wearability, lubrication, fatigue resistance, and external appearance of the material. Surface roughness (mea- 


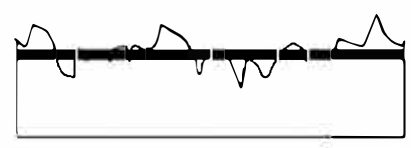

(a)

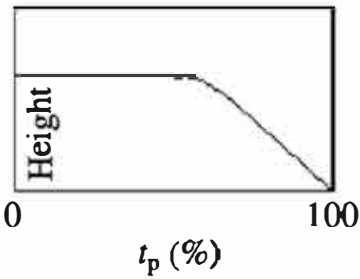

(b)

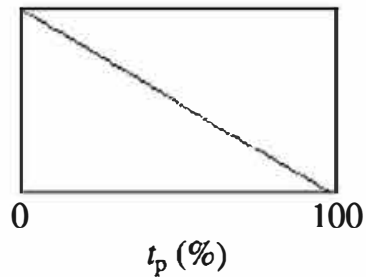

(c)

Figure 1. The Abbott-Firestone curve (a) perznits a qualitative characterization of a material roughness profile representing the section of the profile against the bearing length ratio (b). For homogeneous profiles, the Abbott-Firestone curve represents a straight line with a negative slope (c). Valleys on the surface lead to different graphs.

sured in $\mu \mathrm{m})$ is the most representative parameter to describe the surface texture of a material. All the surface and roughness parameters are included in the standards UNE 82-315/86 [25] and ISO 4287:1997 [26]. The area profile or the AbbottFirestone curve [27] and the average arithmetic roughness, $R_{\mathrm{a}}$ (equation (3)) are important parameters to describe the state of a surface. The first one mathematically describes the cumulative probability density function of the surface profile's height and can be calculated by integrating the profile trace (Fig. 1) and is often used on cylinder liners, for example, to check and predict wear characteristics. $R_{\mathrm{a}}$ represents the arithmetic average of the deviations of the roughness profile from the centreline (previously defined) along the entire length of evaluation $\left(L_{\mathrm{T}}\right)$.

$$
R_{\mathrm{a}}=\frac{1}{L_{\mathrm{T}}} \cdot \int_{0}^{L_{\mathrm{T}}}|y(x)| \mathrm{d} x .
$$

It is also interesting to know the static fiction between the studied polymers [28] because this parameter helps to understand the auto-adhesion between polymeric surfaces. The static friction coefficient is a dimensionless parameter characteristic of each system, which is obtained from the maximum shear strength (equation (4)):

$$
\mu_{\mathrm{s}}=\frac{F_{\mathrm{s}}}{F_{\mathrm{N}}}=\frac{F_{\max }}{m \cdot g} .
$$

In this expression, $\mu_{\mathrm{s}}$ is the static friction coefficient. $F_{\mathrm{s}}, F_{\max }$ and $F_{\mathrm{N}}$ represent the static force between the system components, the maximum force needed to start movement, and the normal force exerted by the gravitational acceleration (it is obtained by multiplying the total mass, $m$, acting on the system and the gravitational acceleration, $g$ ), respectively.

The aim of this work was to achieve a more wettable surface by means of mechanical abrasion, which is a necessary condition prior to adhesive bonding. Changes in the hydrophilic nature of different polymeric substrates with abrasion are studied in terms of SE. 


\section{Experimental Procedure}

\subsection{Materials}

All tests were performed on the surfaces of HDPE, LDPE, PP and silicone samples (Ketersa, Spain). The pieces were treated with sandpapers of different grain sizes $(1000,180$ and 80$)$ and the cleaning and degreasing process was achieved using methylethylketone (MEK).

\subsection{Techniques Used}

\subsubsection{Contact Angle Measurements}

The wettability of both the as-received and abraded samples was evaluated from contact angle measurements using an OCA 15 plus goniometer (DataPhysics, Neurtek Instruments, Eibar, Guipúzcoa, Spain) according to the pr-EN 828:2009 standard [29]. The sample test pieces were placed into the isothermal $\left(25^{\circ} \mathrm{C}\right)$ chamber of the apparatus, which was previously saturated with the vapour of the corresponding test liquid for at least $10 \mathrm{~min}$ before depositing the drops. The test liquids were doubly distilled water, nitromethane, glycerol, diiodomethane and 1,5pentanediol. Drops $(4 \mu \mathrm{l})$ of liquids were placed on the polymer surfaces using an end-fla micrometric syringe (Gilmont Instruments, Barrington, IL, USA). At least six drops per liquid and surface condition were measured and averaged. The experimental error was $\pm 2^{\circ}$. Variations in both components of the SE were studied using the image analysis provided with the SCA20 software and calculated with the OWRK method $[17,18]$.

\subsubsection{Roughness Determination}

The roughness profile of the materials as-received and abraded were measured using a HommelTester T8000 profilomete, following the DIN 4768 standard [30]. The tests pieces were subjected to mechanical abrasion with sandpapers of different grain sizes (1000, 180 and 80), hereafter referred to as S1000, S180 and S80, respectively. Measurements were performed in three directions (parallel, diagonal and perpendicular to the probe) and on both sides of the test piece, thus yielding six values per sample to be averaged.

\subsubsection{Friction Test}

The static coefficien was measured with a tensile machine equipped with a $5 \mathrm{kN}$ load cell following the ASTM D 1894-08 standard [31]. Different standard masses $(0,20,50,100$ and $200 \mathrm{~g})$ were added to the polymer systems in order to vary the $F_{\mathrm{N}}$.

\subsubsection{Scanning Electron Microscopy (SEM)}

Variations in surface morphology with abrasion treatment were evaluated using a Philips XL-30 FEI EUROPE SEM microscope (Eindhoven, Holland). The samples were calculated by gold coating in a Polaron high resolution sputter coater in order to obtain a pathway for electrons due to the nonconducting character of the poly- 
mers and to obtain adequate contrast in the SEM micrographs. The electron beam voltage was $20 \mathrm{kV}$.

\section{Results}

\subsection{Contact Angle Measurements}

In the first step, the pendant drop method was used both in air and n-hexane in order to obtain the reference surface tension values of the test liquids $\gamma_{\mathrm{L}}$ (Table 1), because test liquids of $\gamma_{L}>\gamma_{S}$ are required to calculate the SE of a polymeric material.

In Fig. 2 is observed that water presented the highest contact angles under all conditions tested, followed by glycerol, diiodomethane, 1,5-pentanediol and nitromethane, respectively. It should be noted that a large value of contact angle

Table 1.

Surface tension and its components in $(\mathrm{mN} / \mathrm{m})$ of reference liquids

\begin{tabular}{lllr}
\hline Liquid & $\sigma^{\mathrm{T}}$ & $\sigma^{\mathrm{D}}$ & \multicolumn{1}{c}{$\sigma^{\mathrm{P}}$} \\
\hline Water & $66.6 \pm 0.3$ & $31.5 \pm 0.7$ & $35.1 \pm 0.7$ \\
Glycerol & $61.6 \pm 0.2$ & $37.8 \pm 0.3$ & $23.9 \pm 0.4$ \\
Diiodomethane & $47.5 \pm 0.2$ & $42.2 \pm 0.6$ & $5.4 \pm 0.6$ \\
1.5-pentanediol & $42.4 \pm 0.1$ & $38.6 \pm 0.4$ & $3.8 \pm 0.4$ \\
Niromethane & $35.3 \pm 0.5$ & $31.4 \pm 0.6$ & $3.9 \pm 0.7$ \\
\hline
\end{tabular}

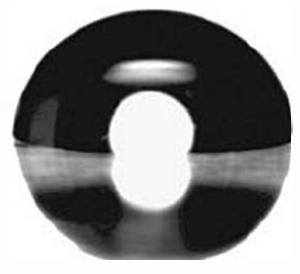

(a)

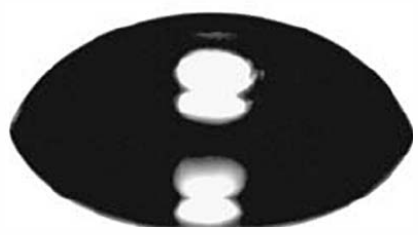

(c)

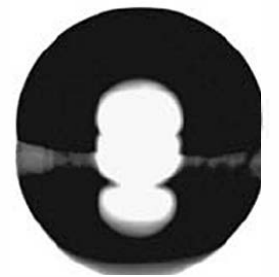

(b)

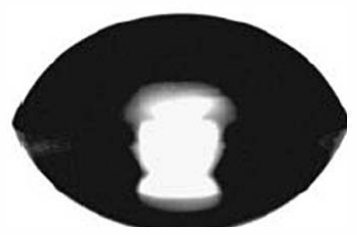

(d)

Figure 2. Droplets of reference liquids over the silicone surface: (a) water, (b) glycerol, (c) diiodomethane and (d) 1,5-pentanediol. 


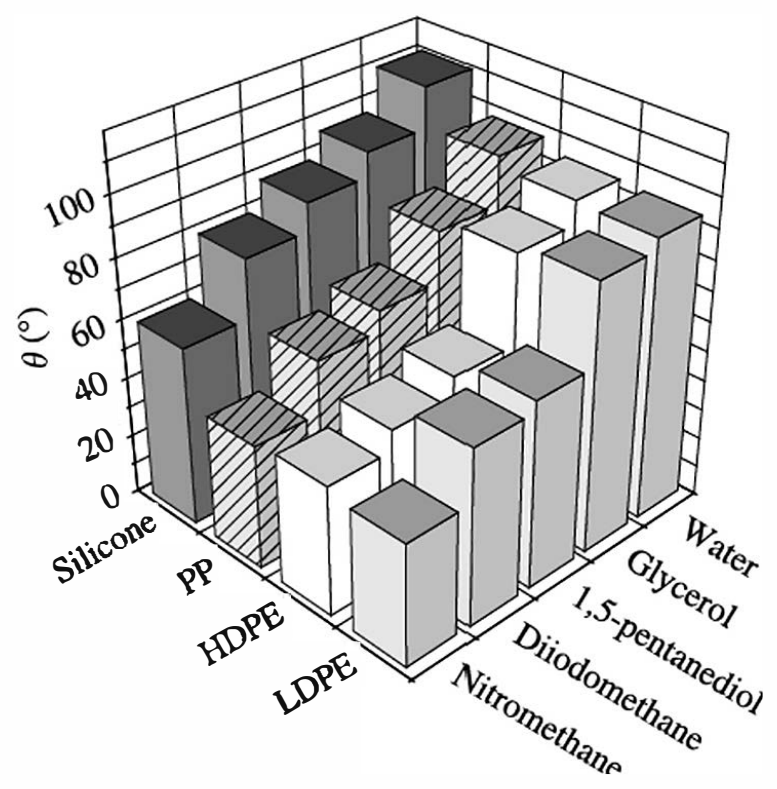

Figure 3. Contact angles on the polymers in the as-received state.

implies a low SE as was described by Young [11] and, therefore, a more hydrophobic and nonpolar surface.

Within the group of tested polymers, HDPE, LDPE and PP showed similar values of contact angles for all test liquids (Fig. 3), therefore no significant difference between their SE values was expected. Nevertheless, the silicone surface presented the largest contact angles so it exhibited the lowest SE. The OWRK calculation of the SE components for the pristine polymers (Fig. 4) showed a predominantly dispersive behaviour (contributions from $99.7 \%$ to $83.5 \%$ of the $\sigma^{D}$ to the total SE for HDPE and silicone, respectively) and low $\sigma^{\mathrm{T}}$ values $\left(26.9 \mathrm{~mJ} / \mathrm{m}^{2}\right.$ for the HDPE and $17.5 \mathrm{~mJ} / \mathrm{m}^{2}$ for the silicone surface), which is in accordance with the nonpolar character of polyolefins and elastomers previously reported by other authors [7-9]. Low values of $\sigma^{\mathrm{T}}$ and $\sigma^{\mathrm{P}}$ are the main cause for the bonding difficulties associated with these polymer surfaces, due to the scarcity of chemically active sites for adhesion.

\subsection{Roughness Test}

The average values of the $R_{\mathrm{a}}$ parameter, corresponding to $95 \%$ confidence level, for both as-received and abraded samples are shown in Fig. 5.

Among all the as-received polymers, the silicone surface presented the highest $R_{\mathrm{a}}$ value, $(0.20 \pm 0.04) \mu \mathrm{m}$, while the PP surface was the smoothest one, with $R_{\mathrm{a}}=$ $(0.08 \pm 0.03) \mu \mathrm{m}$. As it could be predicted, $\boldsymbol{R}_{\mathrm{a}}$ was enhanced when the abrasion condition varied from S1000 to S80, except in the case of the silicone surface, which exhibited an anomalous decrease in $R_{\mathrm{a}}$ from $\mathrm{S} 180$ to $\mathrm{S} 80$. This effect may 


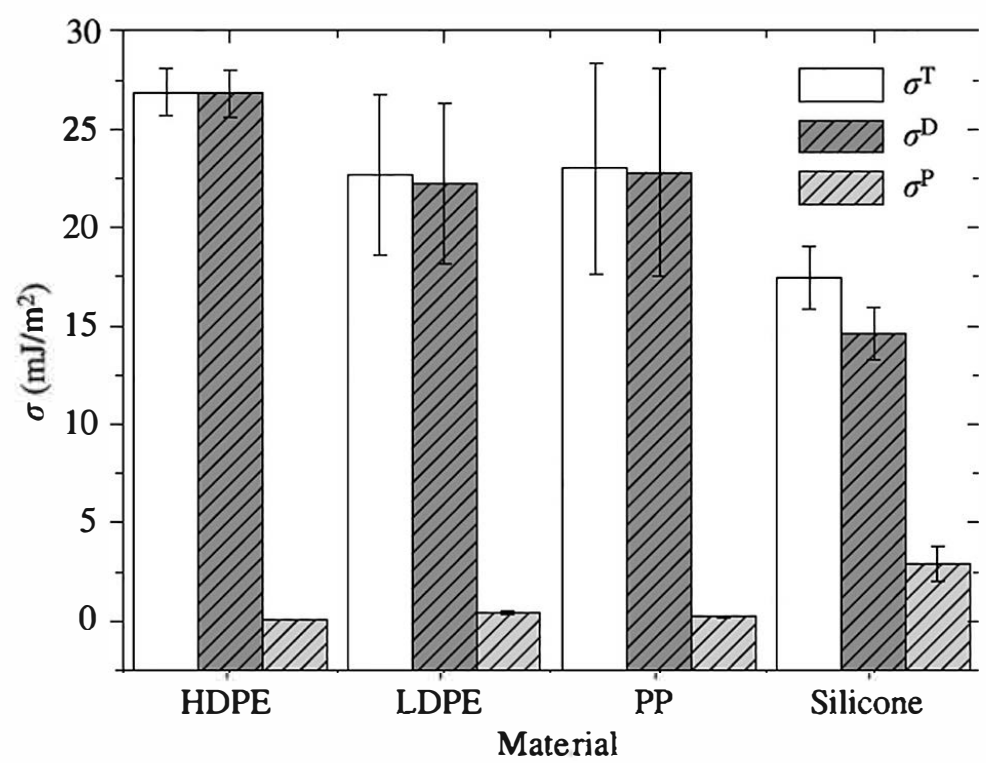

Figure 4. $\sigma^{\mathrm{T}}, \sigma^{\mathrm{D}}$ and $\sigma^{\mathrm{P}}$ of HDPE, LDPE, PP and silicone in the as-received state.

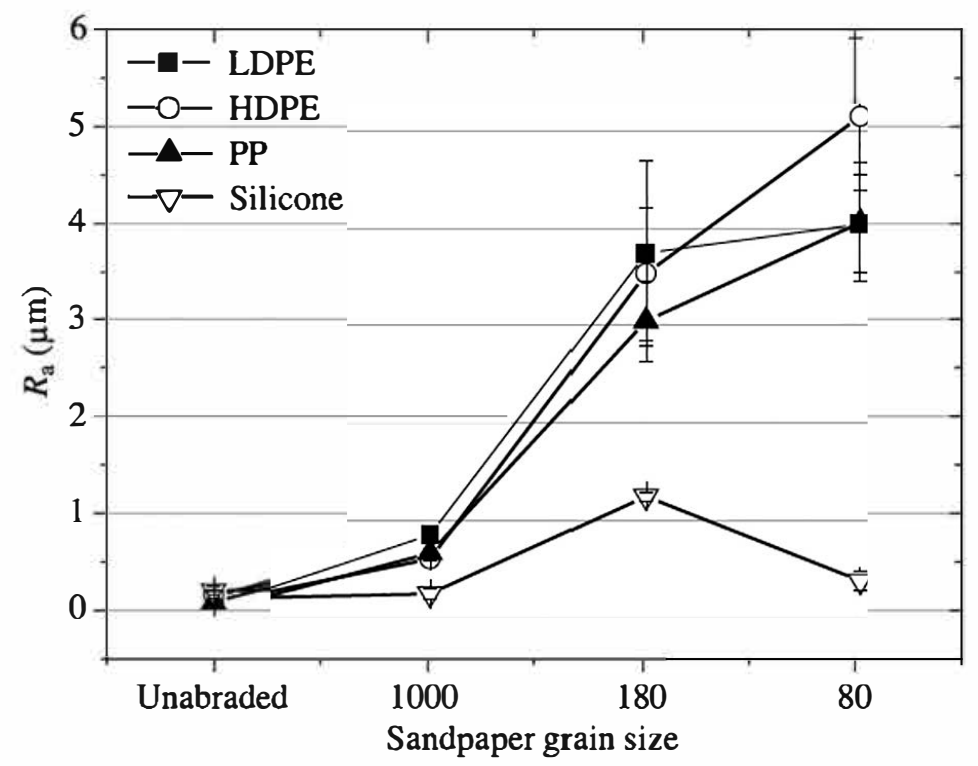

Figure 5. Variation of $R_{\mathrm{a}}$ with sandpaper grain size.

be attributed to the rapid recovery of the silicone surface or to a poor performance of the abrasion process at the S80 sample.

Changes in SE due to the sanding pretreament led to a minimal enhancement in $\sigma^{\mathrm{T}}$ and a constant slight $\sigma^{\mathrm{P}}$ contribution to the total SE (Fig. 6), which is consistent with the nonpolar and hydrophobic nature of this type of surfaces. This 


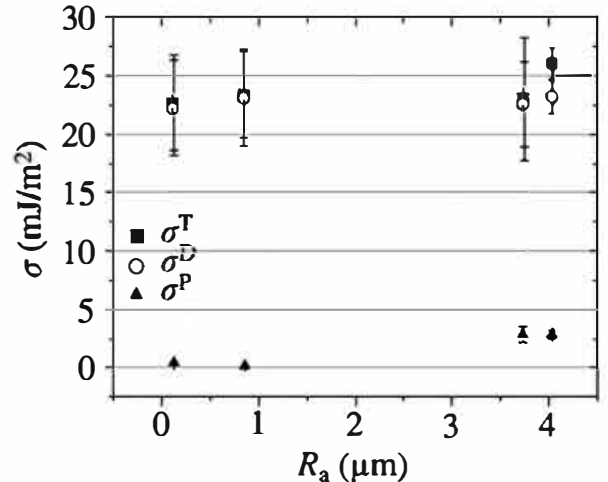

(a)

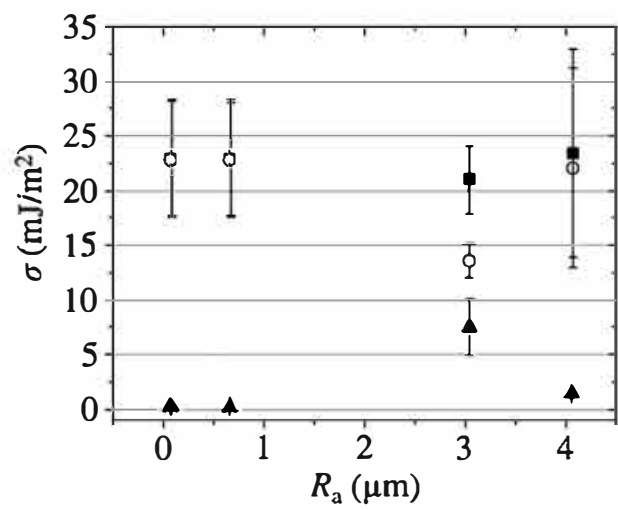

(c)

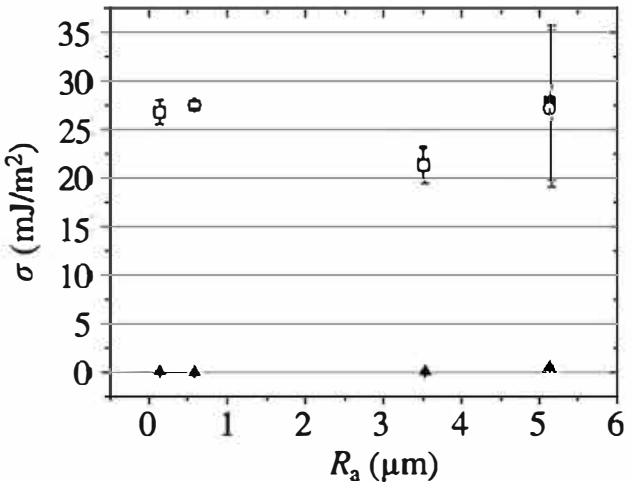

(b)

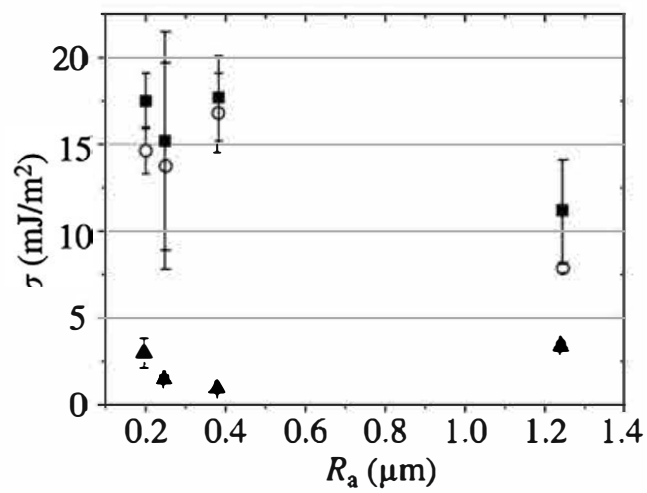

(d)

Figure 6. Evolution of $\sigma^{\mathrm{T}}, \sigma^{\mathrm{D}}$ and $\sigma^{\mathrm{P}}$ with the abrasion treatment in terms of $\boldsymbol{R}_{\mathrm{a}}$ value for (a) LDPE, (b) HDPE, (c) PP and (d) silicone.

non-significant increase in SE induced by mechanical abrasion indicates that this method of surface preparation would be of low effectiveness to improve the wettability and adhesion properties of polymers, although it presents a positive effect on wetting processes in materials with high SE [32] such as metals $\left(>100 \mathrm{~mJ} / \mathrm{m}^{2}\right)$, based on higher macro and microroughness to increase anchoring area for application of the adhesive.

The Abbott-Firestone curves (Fig. 7) confirmed the roughness data shown in Fig. 6 . In the as-received state (Fig. 7(a)), all the polymers presented an almost horizontal trace due to their even surface. Silicone and PP presented the extreme $R_{\mathrm{a}}$ values (0.20 $\mu \mathrm{m}$ and $0.08 \mu \mathrm{m}$, respectively). After S80 abrasion (Fig. 7(d)), HDPE achieved the highest roughness value $\left(R_{\mathrm{a}}=5.15 \mu \mathrm{m}\right)$ which led to AbbottFirestone curves with a steeper slope, while silicone surface just reached $R_{\mathrm{a}}=0.38$ $\mu \mathrm{m}$, and consequently, an almost horizontal Abbott curve. 


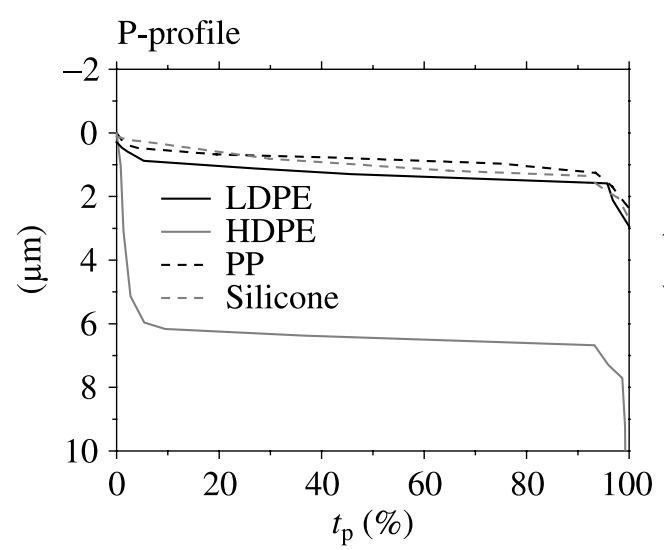

(a)

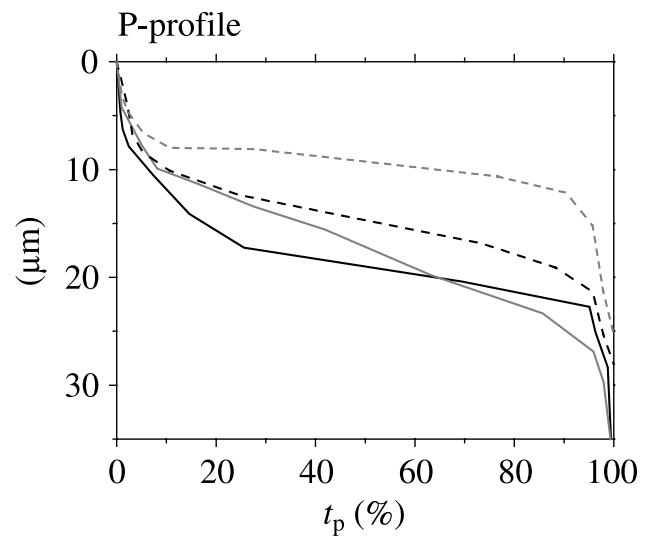

(c)

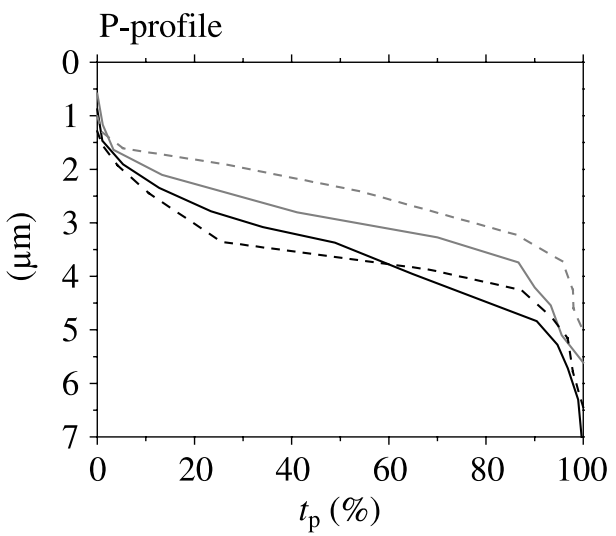

(b)

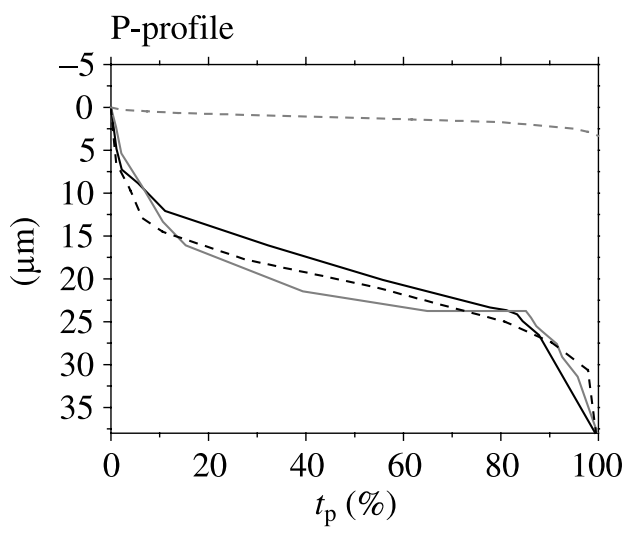

(d)

Figure 7. Abbott-Firestone profile for surfaces in various conditions: (a) untreated, (b) S1000, (c) S180 and (d) S80 treated. The curves represent the length of the studied surface section against the bearing length ratio at different heights above the object's general form $\left(t_{\mathrm{p}}\right)$.

\subsection{Scanning Electron Microscopy (SEM)}

From the SEM micrographs presented in Figs 8-11, it was observed that the abrasion of the polymeric surfaces was much more aggressive as the grain size of the sandpaper varied from S1000 to S80. As-received materials exhibited a large number of defects such as pores, rolling lines or precipitates, which could be due to the synthesis and manufacturing processes of the plastics.

The three polyolefin (Figs 8-10) achieved rougher topographies with the abrasion treatment, which was in agreement with the $R_{\mathrm{a}}$ data obtained by the profilomete (Fig. 5). The Energy Dispersive X-ray (EDX) analysis of the nanoparticles located at the untreated PP surface (Fig. 10(a)) showed a surface composed of carbon, oxygen and titanium, which could be attributed to the existence of unknown additives during the polymer synthesis. In the case of the silicone (Fig. 11), the as- 

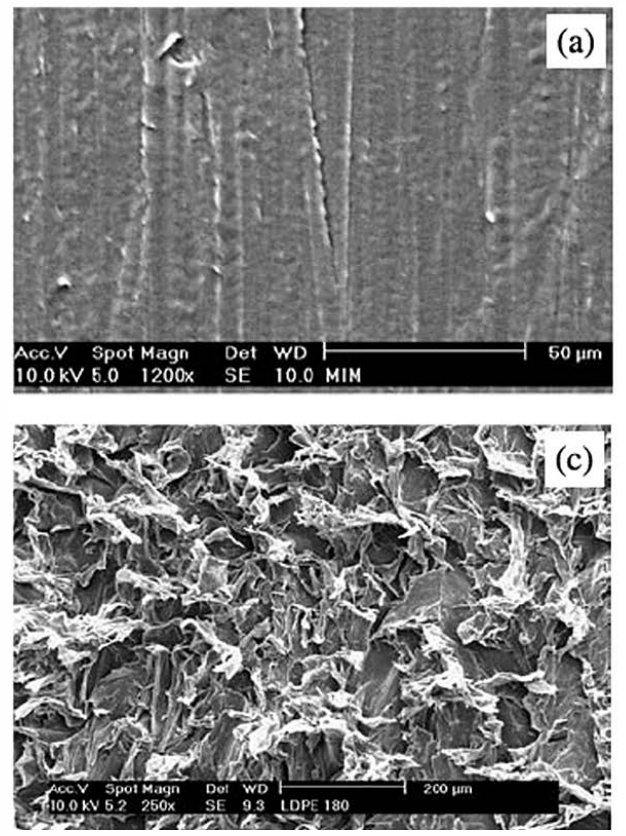
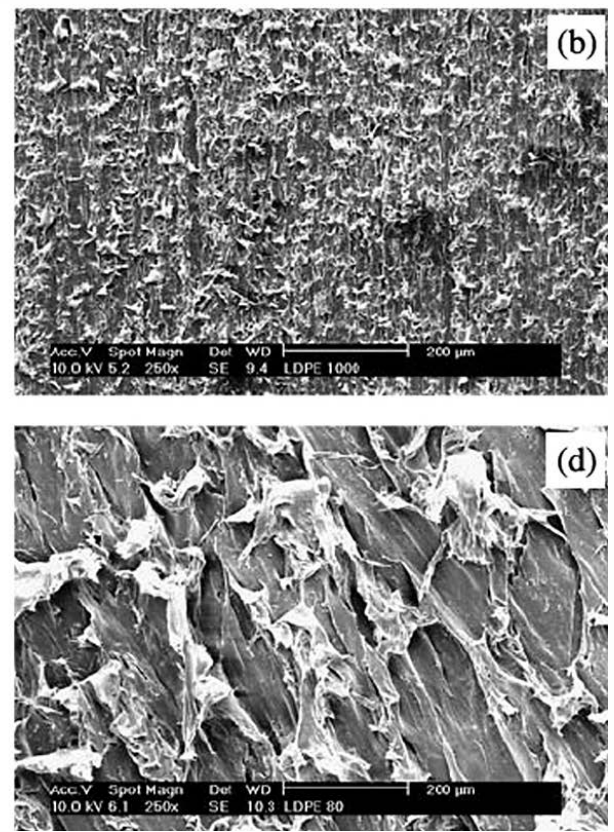

Figure 8. SEM micrographs of the LDPE: (a) untreated, (b) S1000, (c) S180 and (d) S80.
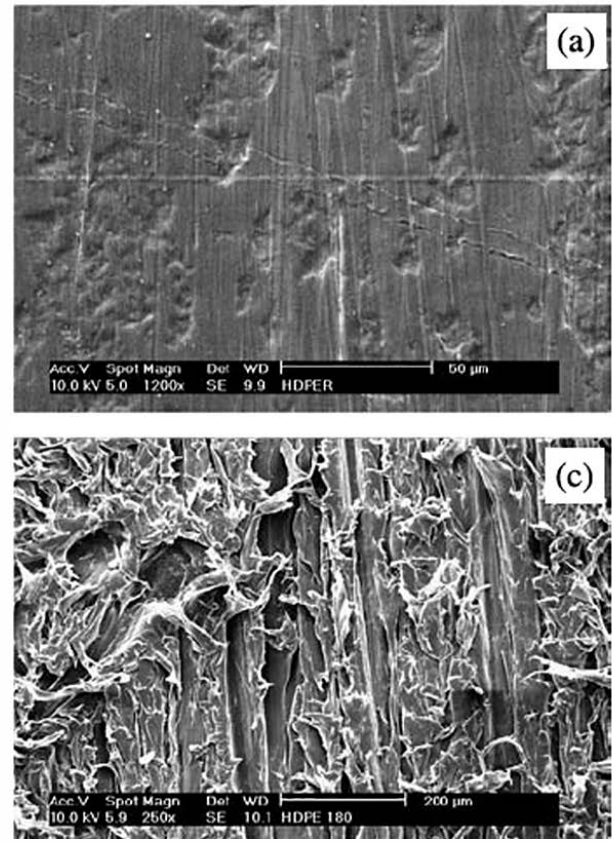
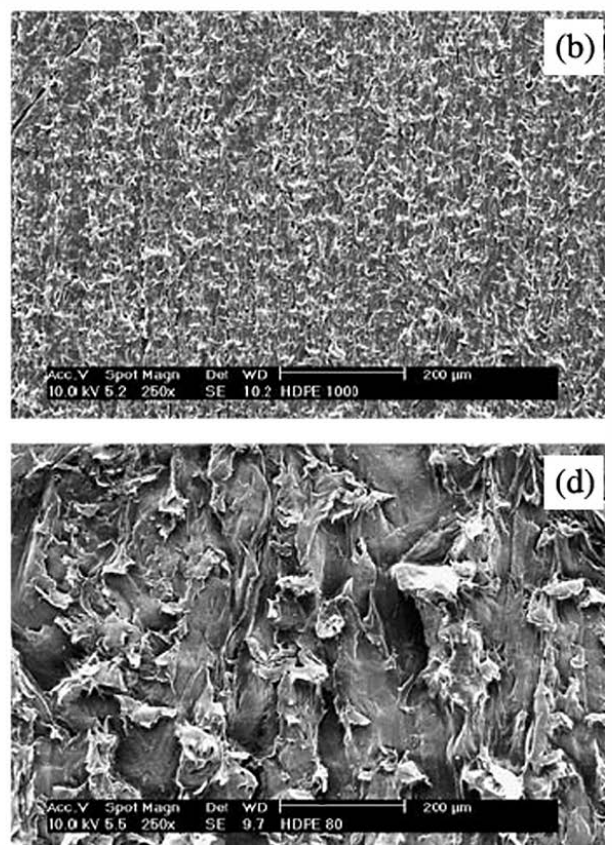

Figure 9. SEM micrographs of the HDPE: (a) untreated, (b) S1000, (c) S180 and (d) S80. 

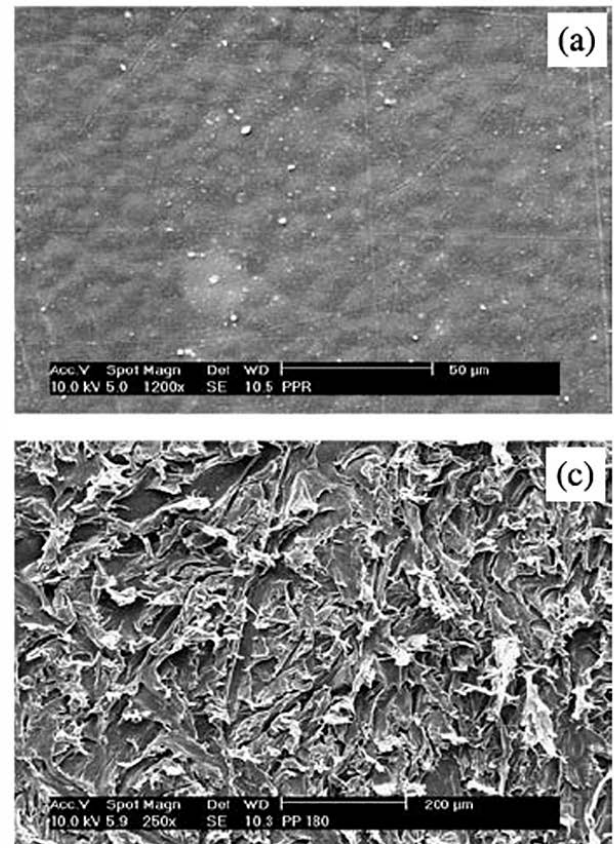
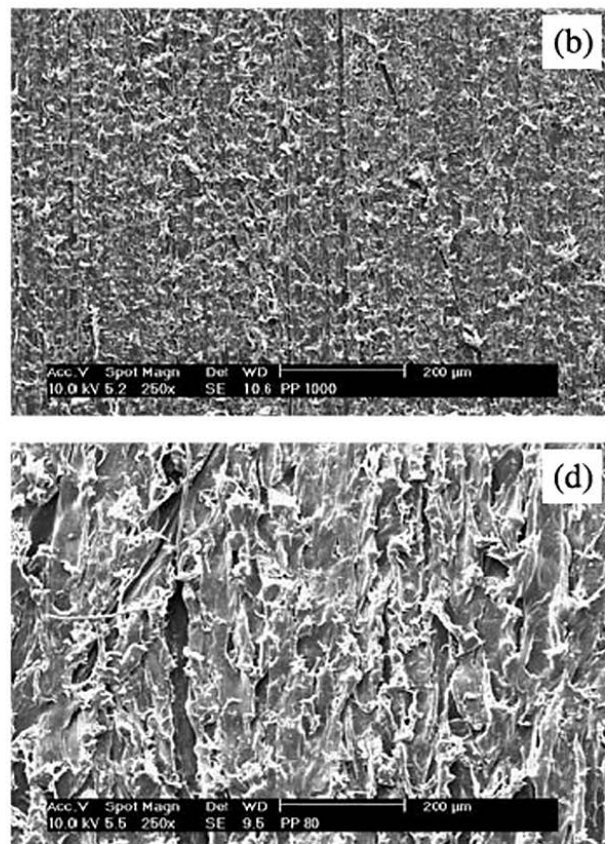

Figure 10. SEM micrographs of the PP: (a) untreated, (b) S1000, (c) S180 and (d) S80.
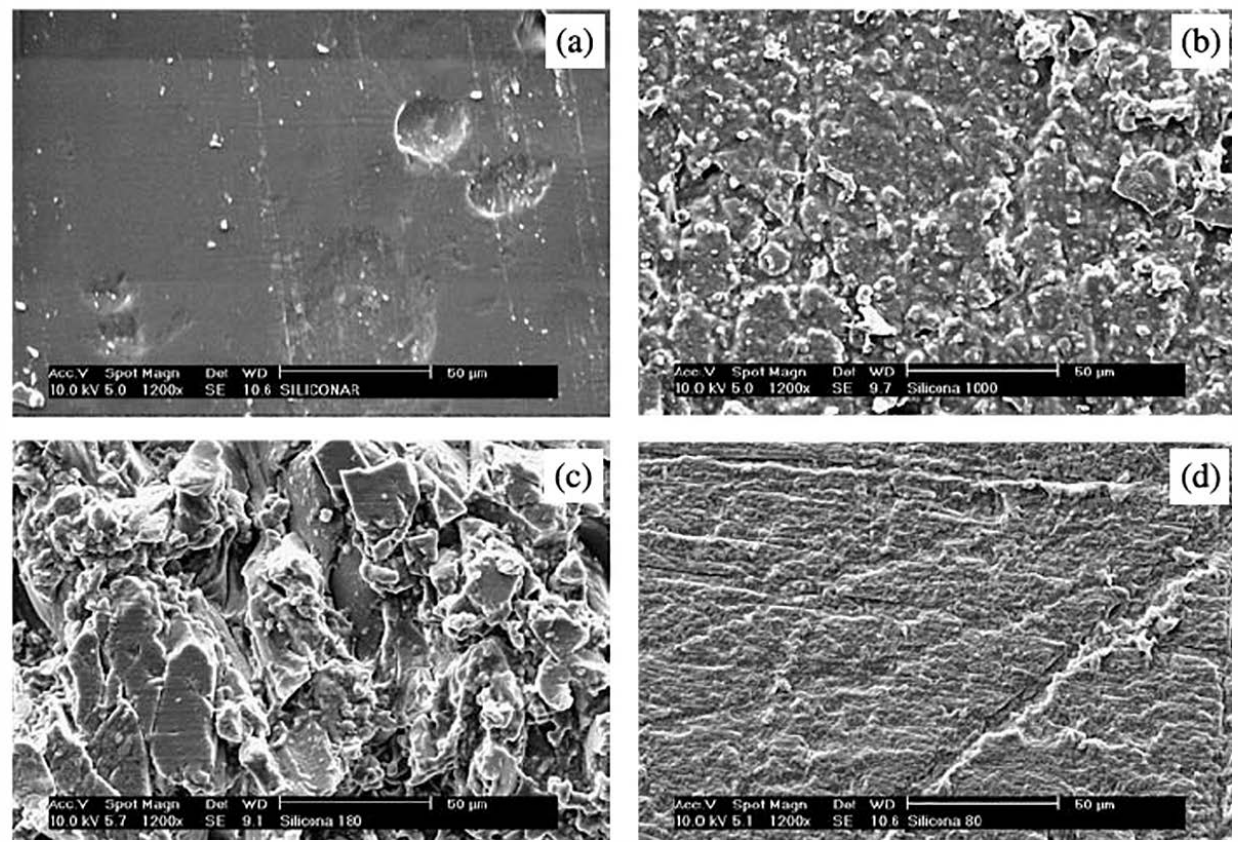

Figure 11. SEM micrographs of the silicone: (a) untreated, (b) S1000, (c) S180 and (d) S80. 
received specimen (Fig. 11(a)) showed craters and precipitates on its surface, and the EDX analysis revealed oxygen, calcium and magnesium. Abrasion with S1000 on the silicone sample created cracks and exfoliation of the surface, but instead of the lamellar structure found in the rest of polymers, islands of rounded profil were created. In the case of the silicone, a higher degradation and rougher surface was achieved for the S180 sample.

\subsection{Friction Test}

The $\mu_{\mathrm{s}}$ was calculated as an average of data experimentally obtained. According to the definitio of the friction coeff cient (equation (4)), $F_{\mathrm{N}}$ was varied by adding different standard masses (Table 2) onto the static mass, in order to obtain different friction conditions.

Variations in $\mu_{\mathrm{s}}$ with increase of $F_{\mathrm{N}}$ are shown in Fig. 12. An increase of $F_{\mathrm{N}}$ led to higher values of $\mu_{\mathrm{S}}$ in all materials [33]. Both LDPE and PP showed higher resistance to motion when abraded with $\mathrm{S} 180$, whereas higher resistance to motion in HDPE and silicone was obtained for the S80 abrasion. It was also observed that, for all the polymers, $\mu_{\mathrm{s}}$ data for the unabraded and $\mathrm{S} 1000$ samples varied by just 0.1-0.2 units. A similar behaviour was found for the S180 and S80 specimens, which presented higher $\mu_{\mathrm{S}}$ values than the unabraded and S1000 samples. In the case of PP (Fig. 12(c)), $\mu_{\mathrm{S}}$ values for the untreated and S1000 samples for the f rst three friction conditions $\left(F_{\mathrm{N}}=1.071,1.267\right.$ and $\left.1.561 \mathrm{~N}\right)$ presented a difference of approximately 0.02 units. Friction values of PP S180 and S80 samples with $F_{\mathrm{N}}$ of $1.071 \mathrm{~N}$ and $1.267 \mathrm{~N}$ were almost equal, and started to become different when the normal force increased to $1.561 \mathrm{~N}$. When the highest $F_{\mathrm{N}}$ value was achieved $(3.031 \mathrm{~N}) \mu_{\mathrm{s}}$ was almost equal for the two abrasion conditions (S180 and S80). In the case of silicone (Fig. 12(d)), $\mu_{\mathrm{s}}$ increased with the normal force and abrasion, in an almost exponential behaviour, with very similar friction values for every abrasion condition at $F_{\mathrm{N}}=1.141,2.121$ and $3.101 \mathrm{~N}$.

\section{Table 2.}

Variation of the applied $F_{\mathrm{N}}$ (calculated by equation (4)) by using various standard masses. The sliding component of the device contributes with a $106.14 \mathrm{~g}$ mass

\begin{tabular}{|c|c|c|c|c|}
\hline \multirow[t]{2}{*}{ Standard mass (g) } & \multicolumn{4}{|l|}{ Material } \\
\hline & $F_{\mathrm{N}}(\mathrm{N}), \mathrm{LDPE}$ & $F_{\mathrm{N}}(\mathrm{N}), \mathrm{HDPE}$ & $F_{\mathrm{N}}(\mathrm{N}), \mathrm{PP}$ & $F_{\mathrm{N}}(\mathrm{N})$, silicone \\
\hline 0 & 1.11 & 1.08 & 1.07 & 1.14 \\
\hline 20 & 1.30 & 1.27 & 1.27 & 1.34 \\
\hline 50 & 2.14 & 1.57 & 1.56 & 1.63 \\
\hline 100 & 2.63 & 2.06 & 2.05 & 2.12 \\
\hline 200 & 3.07 & 3.03 & 3.03 & 3.10 \\
\hline
\end{tabular}




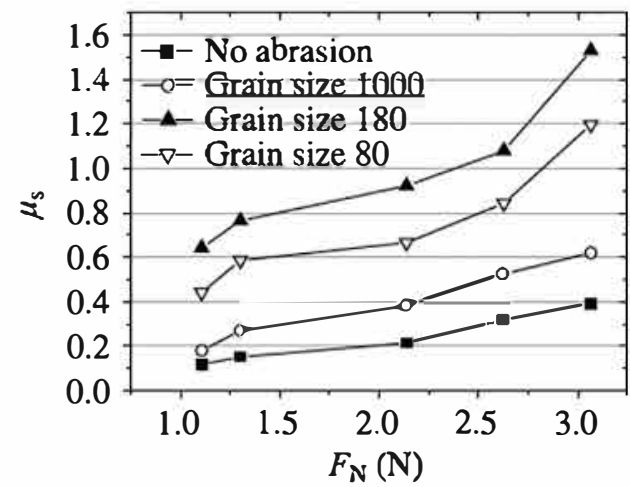

(a)

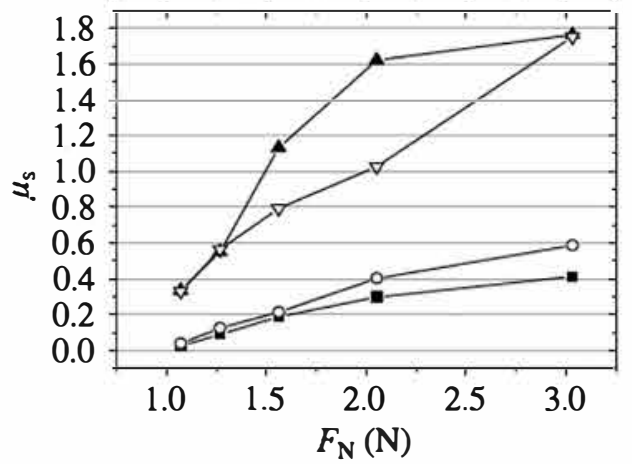

(c)

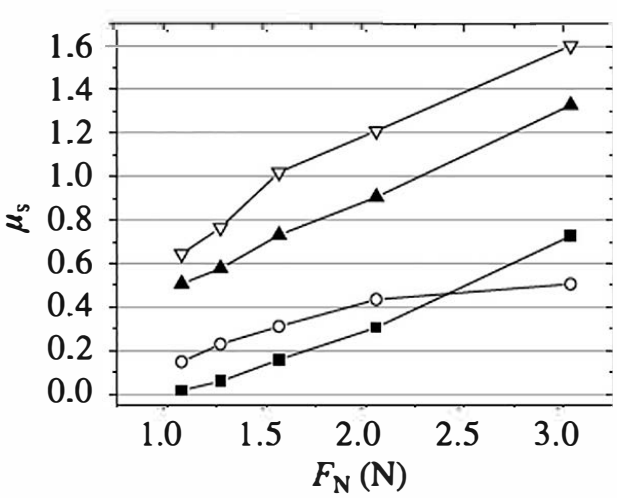

(b)

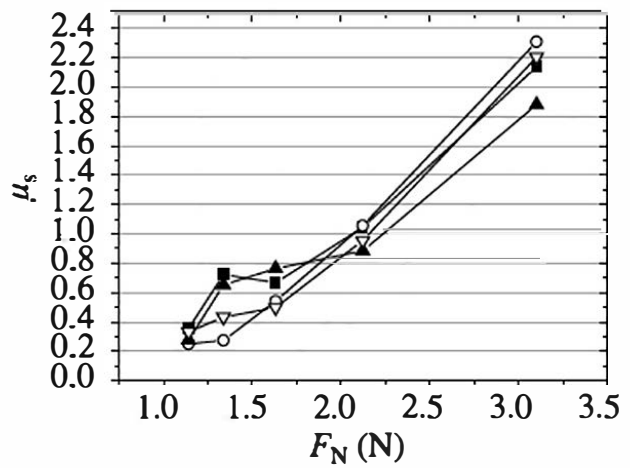

(d)

Figure 12. Variation of $\mu_{\mathrm{S}}$ with $F_{\mathrm{N}}$ for (a) LDPE, (b) HDPE, (c) PP and (d) silicone.

\section{Conclusions}

In this work, a physical pretreatment involving mechanical abrasion was used in order to improve the wettability of four polymers (HDPE, LDPE, PP and silicone) in terms of surface energy increase. Results showed a diminution in contact angle values of the surfaces rom as-received state to the highest sandpaper grain size (S80) $\left(59^{\circ}\right.$ to $46.8^{\circ}$ in the case of diiodomethane onto LDPE), except when abraded at S180 condition, where only a small increase in contact angle was found. However, the experimental error permits to conclude that a general increase in SE with abrasion (from S1000 to S80) was achieved. The slight enhancement (approximately $2 \%$ ) in surface energy seemed to be insufficient to improve the adhesion properties of the studied polymers in terms of wettability.

Morphological characterization obtained by SEM analysis showed the creation of cracks and exfoliation of the material with abrasion. Polyolefins exhibited high numbers of ridges and valleys as treatment was carried out from S1000 to S80. Silicone turned into a degraded surface with islands with rounded profiles instead of the lamellar topography found in the three polyolefins. 
Finally, the static friction coeff cient of each type of material was determined, findin out, as expected, higher difficult for the polymeric samples to start movement (higher friction) as the normal force acting on the polymers increased. Abrasion treatment contributed to enhance the static friction, much more with S180 for LDPE and PP, and with S80 for the PP. In the case of the silicone, although friction reaches the largest value with the normal force increase, it is not possible to determine a clear contribution of sanding to the static friction variation.

\section{Acknowledgements}

Financial support from the Fundación Universidad Carlos III de Madrid and Instituto Tecnológico de Química y Materiales “Álvaro Alonso Barba” is acknowledged.

\section{References}

1. J. M. G. Cowie, Polymers: Chemistry and Physics of Modern Materials, 3rd edn. CRC Press, Boca Raton, FL (2008).

2. E. S. Wilks, Industrial Polymers Handbook: Products, Processes, Applications. Wiley-CH, Weinheim (2001).

3. D. Duval and H. L. MacLean, Cleaner Production 15, 1158-1168 (2007).

4. R. Arshady (Ed.), The PBM Series: Introduction to Polymeric Biomaterials, pp. 162-163. Citrus Books, London (2003).

5. H. S. Cheng, in: Lubrication Regimes, ASM Handbook (Friction, Lubrication and Wear Technology), P. J. Blau (Ed.), Vol. 18, pp. 89-97. ASM International, Metals Park, OH (1992).

6. E. M. Petrie, Handbook of Adhesives and Sealants, p. 225. McGraw-Hill, New York (2000).

7. M. Noeske, J. Degenhardt, S. Strudthoff and U. Lommatzsch, Int. J. Adhesion Adhesives 24, 171177 (2004).

8. A. Kaminska, H. Kaczmarek and J. Kowalonek, Eur. Polym. J. 38, 1915-1919 (2002).

9. D. J. Upadhyay and N. V. Bhat, Plasmas Polym. 8, 237-257 (2003).

10. F. M. Etzler, in: Contact Angle, Wettability and Adhesion, K. L. Mittal (Ed.), Vol. 3, pp. 219-264. VSP, Utrecht (2003).

11. T. Young, Philos. Trans. 95, 65 (1805).

12. W. A. Zisman, Ind. Eng Chem. 55, 14 (1963).

13. W. Wu and G. H. Nancolla, Adv. Colloid Interface Sci. 79, 229 (1999).

14. F. M. Fowkes, J. Adhesion Sci. Technol. 1, 7 (1987).

15. S. Wu, J. Polym. Sci. Part C 34, 19 (1971).

16. R. J. Good, J. Adhesion Sci. Technol. 6, 1269 (1992).

17. D. K. Owens and R. C. Wendt, J. Appl. Polym. Sci. 13, 1741 (1961).

18. D. H. Kaelble, J. Adhesion 2, 66 (1970).

19. K. Gotoh, Y. Nakata, M. Tagawa and M. Tagawa, Colloids Surfaces 224, 165-173 (2003).

20. C. M. Chan, T. M. Ku and H. Hiraoka, Surface Sci. Reports 24, 1-54 (1996).

21. K. L. Mittal (Ed.), Polymer Surface Modification Relevance to Adhesion, Vol. 5. VSP/Brill, Leiden (2009).

22. K. L. Mittal (Ed.), Polymer Surface Modification Relevance to Adhesion, Vol. 4. VSP/Brill, Leiden (2007).

23. M. Matsunaga and P. J. Whitney, Polym. Degrad. Stab. 70, 325-332 (2000). 
24. A. M. Guedes-Pinto, A. G. Magalhaes, F. Gomes da Silva and A. P. Monteiro Baptista, Int. J. Adhesion Adhesives 28, 452-456 (2008).

25. Standard UNE 82-315/86/1, Surface roughness. Terminology. Part I. Surface parameters.

26. Standard ISO 4287:1997, Geometrical Product Specification (GPS): Surface texture: Profil method. Terms, definition and surface texture parameters.

27. E. J. Abbott and F. A. Firestone, J. Mech. Eng 55, 569-572 (1933).

28. P. Stepien, Appl. Math. Modell. 33, 3863-3884 (2009).

29. Standard prEN 828:2009-06-02, Adhesives, Wettability. Determination by measurements of contact angle and surface free energy of solid surfaces.

30. Standard DIN 4768, Determination of roughness parameters by electric palpate devices.

31. Standard ASTM D 1894-08, Standard method for static and kinetic coefficient of friction of plastic fil and sheeting.

32. B. Q. Fu, W. Liu and Z. L. Li, Appl. Surface Sci. 255, 8511-8519 (2009).

33. N. K. Myshkin, M. I. Petrokovets and A. V. Kovalev, Tribology Int. 38, 910-921 (2005). 